\title{
Study on the Problems and Countermeasures of Linyi Hot Spring Tourism Development
}

\author{
Zhaoyun Li \\ Department of State-owned Assets and Laboratory Equipment \\ Linyi University \\ Linyi, China 276000
}

\begin{abstract}
With the rapid development of economy, hot spring tourism is booming in China and gradually changes from the materialized aspect of original pure rehabilitation to the cultural and spiritual aspects of public leisure and health care. Linyi, one of geothermal city in China, has particular rich geothermal resources and hot spring with a long history and cultural resources. The development of Linyi hot spring tourism has great potential. Through the analysis of the current situation and prospect of the development of Linyi hot spring resources, it is found that there are many problems such as similar hot spring tourism products, lack of management and service professionals, lack of local cultural characteristics and so on. And then we put forward countermeasures including precise positioning, highlighting characteristic themes, digging hot spring culture, richening product connotation and broadening the sales channels to promote the healthy development of Linyi tourism.
\end{abstract}

Keywords-hot spring tourism; development situation; problems; countermeasures; Linyi

\section{INTRODUCTION}

Since the mid-90s of last century, with the rapid economic development, hot spring tourism is booming in China and gradually changes from the materialized aspect of original pure rehabilitation to the cultural and spiritual aspects of public leisure and health care. Linyi, one of geothermal city in China, has particular rich geothermal resources and hot spring with a long history and cultural resources. The development of Linyi hot spring tourism has great potential. But at this stage, Linyi do not fully play the greatest advantages and characteristics. We promote the healthy development of Linyi tourism. Through summarizing Linyi hot spring resources, analyzing current situation, looking for prospects and providing some suggestions for the development of Linyi hot spring tourism.

\section{The CURRENT SitUATION OF LiNYI HOT SPRING TOURISM}

Linyi is located in the middle of the Yishu Fault Belt in the Tanlu Large Fault, which is rich in geothermal resources. At present, the geothermal resources in the city are mainly concentrated in the Yishu Fault Belt, the TongzhidianSunzu Fault Belt and the Mengshan Fault Belt. The geothermal resources in Linyi are hot water type. The temperature of geothermal water is between 29 and $80{ }^{\circ} \mathrm{C}$, and partial maximum temperature can reach $82{ }^{\circ} \mathrm{C}$. The main feature of hot water is high contents of fluorine and metasilicic acid. Besides, the hot water also contains lithium, strontium, metaboric acid and other trace elements. So it has high medical and health care value. Linyi has won the title of "China Geothermal City" and "China Hot Spring City". Thirteen hot spring areas in Linyi have been surveyed. Among thirteen areas, ten geothermal fields including Hedong Tangtou, Yinan Tongjing, Yinan Songshan, Yishui Xujiahu, Yishui Longjiayuan, Beicheng New District, Hedong Liuhangtou, Luozhuang Xigaodu, Mengshan tourist area, Xingjiazhuang in Mengshan tourist area have been passed resources assessment and reserves for records by the Shandong Provincial Department of Land and Resources. Hedong Dangtou is one of the four major natural hot springs in the country and Tangtou Hot Spring has been flowing for thousands of years. Yinan Tongjing Hot Spring is suitable for recuperation SPA use. Because the water temperature is high, spring water quality is fine and it contains a variety of chemical ions. The temperature of Pingyi hot spring is homoiothermic in four seasons. It is grown in Ordovician limestone. It has fine water quality and stabilized temperature.

Projects developed in Linyi are mainly concentrated in Hedong, Tangtou and Yinan. Linyi Guantang Hot Spring, Linyi Zhichunhu International Holiday Village and Yutangyuan International Hot Spring Hall were developed in Hedong. Yinan developed Yinan Yishang Hot Spring and Shandong Zhisheng Tangquan Traveling Holiday Village. Yishui developed the East Ruihai International Hot Spring Holiday Village. The main development methods are: hot spring + health, hot spring + health + SPA, hot spring + leisure vacation, hot spring + leisure vacation + sightseeing .

\section{THE PROBLEMS OF LINYI HOT SPRING TOURISM DEVELOPMENT}

\section{A. Hot Spring Tourism Products are Similar}

Although Linyi has a large number of hot spring tourism, the products also have varying degrees of similarity. From the design to the layout of Linyi hot spring tourism have different degrees of similarity. They are mainly manifested as hot spring + health and hot spring + leisure. The people who often go to hot spring for vacation will lose freshness, resulting in some aesthetic fatigue. Hot spring traveling 
Holiday villages that have similar products lack their own characteristics in project, so it is difficult to attract people. The hot spring tourism lacking characteristics will lead to intense competition between hot spring enterprises, or even cause the phenomenon of grabbing tourists and low cost competition.

\section{B. Lack of Hot Spring Management and Service Professionals}

With the increasing diversity of consumer's demand, tourism moves towards internationalization and the general practitioners are more and more difficult to support the development of tourism. Linyi tourism industry is not only lacking professional planning and management personnel, but also lacking appropriate talents in hotel services and other aspects. Many service personnel or managers are residents from nearby rural areas. They can't recognize the role of hot spring tourism played in national economy development, and lack professional knowledge about services and management. Employed persons know very little about local history and culture and folk custom. It is difficult to adapt to the development of modern tourism industry for them. Besides, their mandarin and foreign language level is not high, and service awareness centered on customer is not enough. Hot spring tourism, a new and increasingly popular tourism, is lacking professional management personnel seriously. It has no professional management personnel and no high-quality service team. The limitation of human resources has become one of the important factors in restricting Linyi hot spring tourism development.

\section{Lack of Local Cultural Characteristics in Hot Spring Tourism}

Culture is the soul of tourism. Linyi has deep historical and cultural foundation. The development of hot spring tourism should be complementary with the local cultural development. They are inseparable. In most of Linyi hot spring tourism, there is little depth contact with local culture. The establishment of park and other drifting projects, health care-based SPA centered by the Linyi Hedong Tangtau hot spring tourism resort and the tourist and leisure hot spring holiday village centered by Yinan are lacking some local cultural centers, museums and exhibition halls linked to local culture. Hot spring tourism lacks combination of cultural experience and folk. In the development process, hot spring facilities and products are similar, are not in close connection with their own culture, and lack cultural elements and development characteristics.

\section{Insufficient Efforts in Tourism Marketing}

In Linyi, the main source of hot spring tourists is surrounding source. Most tourists are individual traveler and market share is small. In the process of tourism development and operation, brand awareness is lacking, marketing links are weak and their propaganda is weak. Network marketing lacks characteristics, transparency is not high and the utilization of Internet mobile phone terminal is relatively low. In the long run, visitors will be mainly individual traveler for trip, because the development of traffic is becoming more and more convenient, the short holidays are increasing and self-driving tour is more popular. But in the tourism marketing publicity, it is still lacking certain efforts for individual and peripheral source.

\section{E. Imperfect Infrastructure}

With the rise of hot spring tourism, Linyi can use their advantages to develop hot spring vacation tourism. But some scenic spots develop tourist attractions blindly and ignore the construction of infrastructure driven by economic interests. Part of Linyi hot spring tourist resorts built in county or town has been aroused problems of inadequate facilities construction and incomplete peripheral facilities. For example, some resort facilities are not perfect, parking spaces are lacking, the number of bathrooms is small, and locker room is confined and so on. These issues in short holidays and other tourist peak are particularly prominent, and will affect the long-term development of scenic spots.

\section{COUNTERMEASURES OF LINYI HOT SPRING TOURISM DEVELOPMENT}

\section{A. Doing Precise Position and Highlighting the Characteristics of Theme}

Linyi hot spring tourism products have mainly two modes: hot spring + health and hot spring + leisure. We can change the single mode and embody distinctive features.

1) To combine hot spring with sports: We can combine hot spring with sports. For example, hot spring tourism products of the Lasibao hot spring town in Liaoning Province are combined with many sports. Lasibao is a resort city combined with high-end sports.

Swimming and other water projects are the most closely activity way integrated with the hot spring. We can use the water projects to widen hot spring tourism development.

We can develop traditional sports events with local characteristics and combine with hot spring, and then a near hot spring tourism mode comes into being. It not only makes people enjoy leisure and relaxation of traditional hot spring, but also allows people to experience the infinite joy and enjoyable experience of sports.

2) To combine hot spring with water park projects: We can combine hot spring with water park projects. For example, Shandong Liaocheng Tianmu hot spring have the bath of characteristic function, and also introduce the international popular water recreation facilities. Linyi hot spring tourism should do more improvement on the basis of changing original single mode: hot spring + health and hot spring + holiday.

\section{B. To Strengthen the Quality of Tourism Service Construction and Cultivate Hot Spring Tourism Professionals}

1) Strengthening the cooperation between school and enterprise to cultivate talents: The development of the 
tourism industry now needs a large number of professional high level compound talents who are master of foreign language. The training mode of "school-enterprise cooperation" is one of the important ways to cultivate the required specialized talents who can adapt to tourism area management, tourism services and enterprise services. Although many universities set up Tourism Management Major, the direction of hot spring is less. Regardless of the number or quality, less students studied hot spring tourism direction are difficult to meet the needs of professional talents for Linyi and even the country. Linyi hot spring tourism can use their advantages to establish schoolenterprise cooperation with the major universities and vocational and technical colleges under government's impetus. It can cultivate specialized personnel who adapt to development and construction of scenic spot by means of school plat form. Through the way of school-enterprise cooperation, it can overcome difficulties of lacking professional management personnel in a certain degree.

2) Strengthening the training of staff: Many service personnel or managers are residents from nearby rural areas. Enterprises must strengthen the training of staff to improve the quality of service in the process of solving employment. And then they should build own service team with high quality and high level. Enterprises should strengthen training including etiquette, local culture, history, services, many training and other aspects. If practitioners understand the cultural and historical background of Linyi hot spring better, they can serve customers better.

\section{To Tap the Hot Spring Culture Fully and Enrich Product Connotation}

Linyi, a famous cultural city with ancient history, is a major birthplace of Dongyi civilization. Therefore, the development of hot spring tourism in Linyi should be combined with the unique and rich culture of Linyi.

1) Constructing folk culture of hot spring: Tangtou hot spring is one of the earliest four major natural hot springs. Historical and cultural heritage of Tangtou is very strong. Tangtou hot spring possesses cultural essence of "God, efficiency, benefits, good, blessing, beauty, peace, harmony". Tangtou as the source of Tang River gets its name. In all ages, many literati and historical celebrities have been here. Their arrival pours into a kind of anima for Tangtou hot spring. People have regarded Tangtou hot spring as "God soup" or "God water" through the centuries. It is said that the Spring Festival, Qingming, Futian and Fengshan will be the Tangshen grandmother's time to sprinkle medicine. And then a large number of devotees come here to pray for themselves and their families.

The construction of Tangtou hot spring can combine further with historical celebrities and allusions and legends on the basis of hot spring + health. In order to strengthen the history and culture and explain folk allusions, we can blend culture related to the Tangtou hot spring into the development of hot spring. So that visitors can experience different Tangtou hot spring culture during the hot spring tourism, and experience the unique millennium beauty of here.

2) Combining Yinan hot spring tourism with red tourism culture: Yinan, one of the hot spring tourisms in Linyi, has abundant tourism resources and rich historical and cultural heritage. Yinan, the hometown of Zhu Geliang and Hongsao, has important scenic spots of red tourism in Linyi.

The development of hot spring tourism in Yinan should fully tap its advantages based on the existing mode: hot spring + leisure. It should use the red tourism to further integrate resources and combine with the red tourism culture. In the vicinity of hot spring resort, we can construct local libraries, museums, memorial halls to display the local history and culture and red culture. Through the development of hot spring tourism, we can promote red tourism, and then spread and carry forward the spirit of Yimeng.

3) Combining Linyi hot spring tourism with Yimeng characteristic diet culture: While people are on holiday, it is essential for tourists to experience the local characteristic food. The Linyi hot spring tourism can combine with Yimeng characteristic diet culture.

With the diet programs being popular in China, Linyi special cuisine such as Sa and Yimeng pancake is wellknown and attracts many tourists. Using influential programs and media to publicize Linyi characteristic diet culture, we can make full use of the media to spread the charm of dietary culture. Hot spring tourism should combine with the Yimeng characteristic diet culture to change a single hot spring development mode. At the same time, we should set selfhelp hot spring diet combined with hot springs tourism to let visitors experience the joy of eating by making food.

4) Combining Linyi hot spring tourism with business exhibition: The combination of hot spring tourism and business exhibition needs to base on the rapid development of exhibition business activities. Linyi is not only a famous historical and cultural city, but also a well-known trade city. It is known as "China's capital of logistics". Linyi has become a famous commodity wholesale and distribution center. With the rapid development of Linyi's economy and exhibition industry, the development of exhibition industry has brought new opportunities for the Linyi tourism development.

The combination of Linyi hot spring and exhibition will help to expand the popularity of Linyi hot spring tourism in the whole country and even in the world. Linyi hot spring tourism should fully combine with the characteristics of Linyi logistics city, seize the opportunity and meet the challenges. Using the influence of trade fair and exhibition to expand the influence and publicize Linyi hot spring culture. Then we can attract more tourists to experience the rich hot spring culture in Linyi. 


\section{To Strengthen Marketing Efforts and Broaden Sales Channels}

1) Traditional marketing means: With the development of transportation industry, the increase of short holidays and the popularity of self-driving travelling, tourists more like to travel by themselves. Although self-driving travelling are more and more popular for individual traveler, the percent of loving traditional way of through the travel agency to travel is still large. But in the publicity of traditional tourism marketing, it still lacks a certain intensity efforts for individual and the surrounding tourist. We should make full use of the traditional marketing means, media advertising, store sales and other publicity means to expand popularity.

2) Network marketing: With the maturity of tourist consumption market and the diversification of tourism mode, the Internet platform has become an important way for people to understand the destination of tourism. Therefore, hot spring tourism should follow the pace, make full use of the Internet platform to release information, display scenic spots and attract customers. We should make full use of the Internet mobile terminals. If have ability, we can establish own travel website. Hot spring tourism should follow the trend and use We Chat Official Accounts and other platform to constantly strengthen publicity. We should actively use the Internet platform to carry out some preferential activities to attract tourists, publicize hot spring tourism products and characteristics and expand influence.

\section{E. To Improve Infrastructure Construction}

The modern hot spring tourism has become a travel way for people to choose. During the process of hot spring tourism development, we should pay attention to the supporting infrastructure construction. Firstly, we can increase capital investment to improve infrastructure such as the expansion of parking lot, the improvment of locker room, the improvment of sanitation and environment etc.. Secondly, in order to effectively cope with traffic jams at rush hour, scenic spots can set special bus to give tourists convenience to travel or cooperate with hotels and travel agencies to deal with traffic problems.

\section{CONCLUSION}

With the development of leisure tourism, Linyi hot spring tourism is also developing continuously. The hot spring tourism resources in Linyi are rich, and the development of hot spring tourism should combine with own characteristics and culture. We should change a single development mode, develop hot spring tourism having own characteristics, constantly promote and improve own development, forming a perfect hot spring service system and take Linyi characteristic hot spring tourism road.

\section{REFERENCES}

[1] He Xiaoqian, Liu Yu, Wu Faming. Analysis on Temporal and Spatial Characteristics of Network Attention of Hot Spring Tourism Based on Baidu Index[J]. AREAL RESEARCH AND DEVELOPMENT, 2017, 36 (1): 103-108.

[2] Andrew P, Yingmiao Y. The Internet and the Occidental Tourist: An Analysis of Taiwan's Tourism Websites from the Perspective of Western Tourists [J]. Information Tech-nology and Tourism, 2005, 7(7): 91-102.

[3] ZHENG Yaoxing, DENG Xiaoying, RUAN Yongming. Hot Spring Tourism Development Research Based on Women Behavior Perspective-Take Fuzhou Hot Spring Resort Gui'an Case[J].Journal of Chongqing University of Arts and Sciences (Social Sciences Edition), 2016, 35(3): 142-145.

[4] LIU Jing. Research on Upgrading the Quality of the Hot Spring Tourism in FU Xin under the New Normal State[J]. Journal of Tongren University, 2015, 17 (6): 171-176.

[5] CAI Tianshu, YUAN Qifeng, HUANG Zhe. Local Community Participation in Urban Tourism Development: A Case Study Based on Nanjing Tangshan Hot Springs Tourist Town[J]. Urban Development Studies, 2015, 22 (10): 71-80.

[6] YANG Yi, LIU Qing. Development Path on Experience-Based Thermal Spring Tourism[J].China Population, Resources and Environment. 2015, 25 (5): 86-90. 